\title{
Tariff policy for a monopolist in a signaling game
}

\author{
Dobrin R. Kolev ${ }^{\mathrm{a}}$, Thomas J. Prusa ${ }^{\mathrm{b}, \mathrm{c}, *}$ \\ ${ }^{\mathrm{a}}$ Mitchell Madison Group, 520 Madison Avenue, New York, NY 10022, USA \\ ${ }^{\mathrm{b}}$ Department of Economics, Rutgers University, New Brunswick, NJ 08901-1248, USA \\ ${ }^{\mathrm{c}}$ Natural Bureau of Economic Research, Cambridge, MA, USA
}

Received 3 July 1997; received in revised form 13 February 1998; accepted 2 March 1998

\begin{abstract}
We examine the incentives for a government to levy an optimal tariff on a foreign monopolist with unknown costs. With complete information, the home government uses a discriminatory tariffs policy to extract rents. If the government is incompletely informed about costs, we show that under reasonable conditions the unique equilibrium involves pooling where the firm exports the same quantity regardless of its efficiency. We find that in general home welfare is higher under alternative policies such as uniform tariffs or free trade, suggesting that trade policies that are motivated by rent extraction are unlikely to be robust to the introduction of incomplete information. (c) 1999 Elsevier Science B.V. All rights reserved.
\end{abstract}

Keywords: Tariffs; Monopoly; Incomplete information; Signaling

JEL classification: F13; D82; L12

\section{Introduction}

The insight that a small positive tariff will cause a welfare-improving terms of trade effect is one of the fundamental explanations for the existence of trade

\footnotetext{
*Corresponding author. Tel.: (1-732)-932-7670; fax: (1-732)-932-7416.

E-mail address: prusa@econ.rutgers.edu (T.J. Prusa)
} 
restrictions. ${ }^{1}$ Even though the standard analysis is conducted within a perfectly competitive framework (Johnson, 1951), the incentive to use trade policy to manipulate the terms of trade emerges in a variety of market structures and technologies. ${ }^{2}$

The economics underlying the terms of trade effect is perhaps most clearly stated when the domestic market is serviced by a foreign monopolist (Katrak, 1977; Brander and Spencer, 1984). If demand is not too convex, a small positive tariff will cause the price of the product to rise by less than the full amount of the tariff. On net, the loss in consumer surplus is more than compensated by the gain in tariff revenue. Hwang and May (1991) further develop Katrak's (1977) insight and show that the size of the tariff is directly related to the efficiency of the foreign supplier: the more efficient is the monopolist, the larger is the optimal

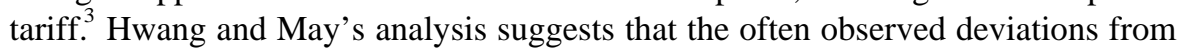
uniform tariff levels are due at least in part to the government's desire to fine-tune their tariff structure to the exporter's efficiency. That is, exceptions will be sought against efficient suppliers (i.e., high tariffs such as antidumping and countervailing duties); on the other hand, custom unions or preferential trading arrangements (i.e., NAFTA and the Caribbean Basin Initiative) will be formed with countries whose firms are relatively inefficient.

A key assumption implicit in a model of discriminatory tariffs is that the government has complete information about, or is able to observe, the technology of the foreign supplier. If the government cannot observe costs, then the terms of trade incentive to deviate from uniform tariffs may disappear. The reason is that the foreign firm has an incentive to alter its exporting behavior in order to convince the government that it is an inefficient firm. And, if the foreign firm always acts as if it is inefficient, a discriminatory tariff policy leads to uniform low tariffs. On the other hand, an explicit commitment to a uniform policy would have similar terms of trade effects, but without distorting the incentives for the monopolist to trade.

Thus, the main question we address in this paper is whether a policy of discriminatory tariffs makes sense for a government with incomplete information

\footnotetext{
${ }^{1}$ There are many other explanations for the widespread use of trade restrictions, including rent-seeking, political pressures (Grossman and Helpman, 1994, 1995a,b), increasing returns to scale (Krugman, 1984), and profit-shifting motives (Brander and Spencer, 1984).

${ }^{2}$ Feenstra (1995) offers an excellent summary of the terms of trade driven incentives for trade restrictions in both perfectly and imperfectly competitive models. Bagwell and Staiger (1996) argue that the terms of trade effect explains not only why tariffs are levied but also why unilateral liberalization (beyond the Nash tariff level) is rarely observed. They argue that the desire to escape from terms of trade driven prisoners' dilemma is the primary reason why countries enter into reciprocal trade agreements.

${ }^{3}$ While the idea of imposing duties as a function of the efficiency of a foreign exporter is implicit in the optimum tariff arguments of Katrak (1977), Hwang and May (1991) were the first to explicitly develop the result, albeit in a duopoly setting.
} 
about the foreign firm. In order to answer this question, we develop a multi-period model where the foreign firm's efficiency is private information. In the first period foreign products are allowed to enter at a pre-existing tariff level. Upon observing the firm's first period exports, the government levies a tariff on future period trade. From a technical viewpoint, the model is essentially a signaling game where we seek to determine whether the outcome involves pooling or separation and whether in light of the signaling problem a discriminatory policy is superior to a commitment to uniform tariffs.

There are several key findings. First, we show that there is always a unique stable Nash equilibrium. In particular, we show that the type of equilibrium to emerge - separating or pooling — depends on the size of the discount rate (relative to cost and demand parameters). If the discount rate is sufficiently large, pooling is the unique equilibrium; on the hand, if the discount rate is relatively small, separation is the unique equilibrium. Second, we show that a policy of discriminatory tariffs will typically lower welfare, suggesting that the welfare results of Katrak (1977), Brander and Spencer (1984) and Hwang and May (1991) depend crucially on the assumption of full information. Specifically, we show that a policy of uniform tariffs is always preferred whenever the discount rate is sufficiently large to result in pooling and is usually preferred when separation is the unique equilibrium. Third, our model highlights the importance of the 'single crossing' assumption which is typically made in signaling models. We show that our model falls into the category of signaling games with 'double crossing' as defined by Kolev (1995). By double crossing we mean that the payoff function of the party with private information does not satisfy the usual monotonicity with respect to type. As a result the typically observed separating equilibria are rather fragile and the unique self-enforcing outcome is likely to involve pooling where exports are restricted regardless of the true type of the foreign firm.

Our paper complements a growing body of work incorporating incomplete information in strategic trade policy models, all of which in one from or another draw into question the robustness of benefits of rent extraction policies. The papers of Qiu (1994) and Collie and Hviid (1993, 1994) are the most closely related to the signaling approach developed in this paper. The first two papers use third market models in which a foreign firm is incompletely informed about the costs of a domestic producer. Qiu's (1994) model is a combination of screening and signaling, where he shows that a separation-inducing menu must involve subsidies proportional to efficiency. Collie and Hviid (1993) show that governments have an incentive to oversubsidize exports in order to signal the domestic firm's efficiency and soften foreign competition. In a model with a foreign monopolist who has incomplete information about domestic demand, Collie and Hviid (1994) show that the unique separating equilibrium involves excessive duties. All of these models are characterized by the usual single crossing property and thus all result in separating outcomes. Our analysis highlights the relevance of pooling outcomes. More recently, Brainard and Martimort (1997) have extended the basic Brander- 
Spencer duopoly game to allow both firms to have private information and to allow both governments to strategically use trade policy. They adopt a screening approach and find that the informational asymmetry reduces the optimal subsidy (and may even imply that an export tax is optimal).

The remainder of the paper is organized as follows. In Section 2 the basic model is developed, and in Section 3 we solve for the benchmark complete information discriminatory tariff. In Section 4 we solve for the optimal tariff under incomplete information and show how the discount factor crucially influences the equilibrium outcome. In Section 5 we analyze the welfare consequences of government's limited information. Concluding comments and extensions are discussed in Section 6.

\section{The basic model}

We assume that there is a single multinational firm who serves the domestic market. The sequence of moves in the game we have in mind is as follows. At time zero the constant marginal cost of the foreign firm is drawn from the set $\mathscr{C}=\left\{c_{l}, c_{h}\right\}, c_{l}<c_{h}$, according to a commonly known probability distribution. Let $\mu$ be the probability that the monopolist is efficient (i.e., has cost $c_{l}$ ). The true realization of the draw is private information for the exporter. The assumption of constant marginal costs is convenient since it allows for an independent analysis of the export decision.

Exporting takes place over an infinite number of periods. In the first period the firm chooses a quantity from the positive orthant under conditions of free trade. After observing the level of imports the government forms beliefs about the type of firm servicing its market and selects a per unit tariff, $\tau$. We limit the ability of the government to intertemporally change its policy by assuming that the tariff will be in effect for the remainder of the game. Given the chosen tariff, in each period the multinational makes its output decision and payoffs are realized.

We work with the standard model of Katrak (1977) where $q_{t}$, the demand for the imported product in period $t$ in the home country, is derived from a quasi-linear utility function which yields an inverse aggregate demand function of the form

$$
p_{t}=a-q_{t}, \quad t=1, \ldots, \infty .
$$

\section{The complete information tariff}

In order to highlight the distortions caused by asymmetric information, we begin by examining the optimal tariff when the home government has full information

\footnotetext{
${ }^{4}$ Assuming free trade in the first period is without loss of generality. Any exogenously given tariff at this time would leave the qualitative features of the model intact.
} 
about the firm's costs. In period $t, t \geq 2$, the multinational takes $\tau$ as given. Its variable profit function can be written as

$$
\pi_{t i}=q_{t}\left(a-q_{t}\right)-\tau q_{t}-c_{i} q_{t}, \quad t=2, \ldots, \infty,
$$

where $i$ denotes the firm's type (cost realization), $i=l, h$. For convenience, we will refer to a high cost firm as $h$ and a low cost firm as $l$. The resulting optimum quantity and profit for a type $i$ firm in each period are

$$
q_{i}(\tau)=\left(a-c_{i}-\tau\right) / 2 \text { and } \pi_{i}(\tau)=\left(a-c_{i}-\tau\right)^{2} / 4
$$

The home government chooses $\tau$ in order to maximize discounted national welfare, $W=\Sigma_{t=2}^{\infty} \delta^{t-1} w_{t}$, where $\delta$ is the discount factor. Welfare is defined as the sum of consumer surplus and tariff revenue. Given linear demand we can write period $t$ welfare as

$$
w_{t}=q_{i}(\tau)^{2} / 2+\tau q_{i}(\tau), \quad t=2, \ldots, \infty .
$$

Since maximizing total welfare (post-tariff) is equivalent to maximizing per period welfare we can substitute the firm's unique best quantity response, $q_{i}(\tau)$, into Eq. (2)

$$
w_{t}=\left(a-c_{i}-\tau\right)^{2} / 8+\tau\left(a-c_{i}-\tau\right) / 2, \quad t=2, \ldots, \infty .
$$

Maximizing Eq. (3) with respect to $\tau$ yields an optimal tariff of

$$
\tau_{i}^{o}=\left(a-c_{i}\right) / 3 \text {. }
$$

The equilibrium tariff, which is the same as the one obtained by Katrak (1977), shows the clear incentive for the home country to exploit its information and levy a tariff proportionate to the efficiency of the exporter.

Given that the government observes realized costs, the firm's optimal first period decision is to simply sell the monopoly output, $q_{1 i}^{o}=\left(a-c_{i}\right) / 2$. This implies the firm's total profit (over all periods) is

$$
\pi_{i}^{o}=\pi_{i}(0)+\sum_{t=2}^{\infty} \delta^{t-1} \pi_{i}\left(\tau_{i}^{o}\right)=\frac{\left(a-c_{i}\right)^{2}(9-5 \delta)}{36(1-\delta)} .
$$

\section{Tariff policy with incomplete information}

We now return to the assumption that the government does not observe the firm's cost realization. By introducing private information on the part of the firm we explore the possibility that the producer can act strategically in the first period in order to influence the posterior beliefs and the subsequent choice of tariff by the government. A deviation from the monopoly level of output is costly and it can serve as a natural credible signal which the firm can employ to transmit information about its technology. From Eq. (3) note that $\partial W / \partial \tau$ is strictly decreasing in $c_{i}$. This means that the benefit of the home country from lowering 
the tariff rate is strictly increasing in cost which in turn implies that the government's best response function is strictly decreasing in the posterior likelihood of $h$. And, from the analysis of the prior section it is evident that the exporter would like the government to believe that it is inefficient so that it faces lower duties.

\subsection{The solution concept}

We restrict our attention to sequential equilibria in the sense of Kreps and Wilson (1982) as adapted to signaling games with continuum of strategies by Kreps and Sobel (1994). In short, sequential equilibria require that: (i) both players maximize their respective payoff functions given the strategy of the other and the beliefs of the government (sequential rationality); and (ii) the set of posterior beliefs at each quantity level rationalizes the government's behavior in a manner compatible with Bayes' theorem at non-null events (consistency).

It is obvious that in any sequential equilibrium the firm will choose the monopoly level of exports and earn the corresponding profit in each period following the imposition of the tariff. If the state is able to correctly infer the technology and impose its optimal tariff, the best the monopolist can do is (substituting Eq. (4) into Eq. (1)

$$
q_{t i}^{o}=\left\{\begin{array}{cc}
\left(a-c_{i}\right) / 2 & t=1, \\
\left(a-c_{i}\right) / 3 & t=2, \ldots, \infty
\end{array}\right.
$$

and

$$
\pi_{t i}^{o}=\left\{\begin{array}{cc}
\left(a-c_{i}\right)^{2} / 4 & t=1, \\
\left(a-c_{i}\right)^{2} / 9 & t=2, \ldots, \infty .
\end{array}\right.
$$

It is also easy to show that, as usual in signaling games, there is a continuum of pooling, semi-pooling, and separating equilibria due to the wide range of permissible beliefs about the type of the monopolist which the government may entertain off a sequential equilibrium path. Most of these systems of beliefs are unreasonable, however, and we will further refine the set of sequential equilibria by employing the $D_{1}$ criterion of Cho and Kreps (1987) which is based on the notion of divinity of Banks and Sobel (1987). In essence, this requires the government to place probability one on the type more likely to produce a particular out of equilibrium quantity. To formalize the idea, let us fix a sequential equilibrium outcome (i.e., a probability distribution over the end points of the game induced by a sequential equilibrium) in which an exporter of type $i$ obtains total profit $\pi_{i}^{*}$. For an out of equilibrium quantity $q_{1}$ define the set

$$
E_{i}^{0}\left(q_{1}\right) \equiv\left\{\tau \in B R\left(\eta, q_{1}\right): \pi_{i}\left(q_{1}, \tau\right)=\pi_{i}^{*}\right\},
$$

where $B R\left(\eta, q_{1}\right)$ is the set of best responses of the government at $q_{1}$ given that the 
induced beliefs about the types exporting this quantity are $\eta . E_{i}^{0}\left(q_{1}\right)$ is thus the set of best responses which would leave $i$ indifferent between his equilibrium strategy and exporting $q_{1}$. Likewise, the set of sequentially rational tariffs which would make $i$ strictly better off is denoted by

$$
E_{i}\left(q_{1}\right) \equiv\left\{\tau \in B R\left(\eta, q_{1}\right): \pi_{i}\left(q_{1}, \tau\right)>\pi_{i}^{*}\right\} .
$$

We say that a sequential equilibrium is $D_{1}$ if and only if, at each off equilibrium quantity $q_{1}$, it can be supported with beliefs $\eta\left(i \mid q_{1}\right)=0$ whenever

$$
E_{i}^{0}\left(q_{1}\right) \cup E_{i}\left(q_{1}\right) \subseteq E_{i^{\prime}}\left(q_{1}\right)
$$

for $E_{i^{\prime}}\left(q_{1}\right) \neq\{\varnothing\}$. An outcome arising from a $D_{1}$ equilibrium will be termed a $D_{1}$ outcome. The intuition behind the divinity refinement is that whenever $i$ wants to deviate from a particular equilibrium, $i^{\prime}$ also does, which makes $i^{\prime}$ the more likely type to break the proposed play.

As is well known, there are a number of refinements of equilibria used in signaling games. Similar to the $D_{1}$ criterion in both intuition and game theory justification are the Intuitive Criterion and the $D_{2}$ criterion (Cho and Kreps, 1987). In general $D_{2}$ is more stringent than $D_{1}$ because it further restricts the strategy spaces of the players. Formally, the steps in applying $D_{2}$ are the same as the ones outlined above for $D_{1}$, except Eq. (6) should be replaced with

$$
E_{i}^{0}\left(q_{1}\right) \cup E_{i}\left(q_{1}\right) \subseteq \cup_{i^{\prime} \neq i} E_{i^{\prime}}\left(q_{1}\right) .
$$

In our case, since we only have two types the $D_{1}$ and $D_{2}$ concepts are equivalent.

On the other hand, the Intuitive Criterion is a weaker refinement than $D_{1}$. At an out of equilibrium quantity $q^{\prime}$, the Intuitive Criterion requires assigning probability one to a given type $i$ if in combination with the lowest possible sequentially rational tariff $q^{\prime}$ is: (1) preferred by $i$ to the proposed equilibrium; and (2) is not preferred to the proposed equilibrium by the other type. However, the Intuitive Criterion does not provide a systematic way to assign beliefs if at $q^{\prime}$ both types prefer the lowest tariff to the proposed equilibrium.

It is well known that if there are two types and if the profit function of the monopolist exhibits the single crossing property, then no pooling equilibria survive the Intuitive Criterion. In fact, the Intuitive Criterion selects the unique selfenforcing equilibrium of the game and this equilibrium is separating. ${ }^{5}$ However, as we show in Lemma 1 the single crossing property is not a characteristic of the profit function of the monopolist in our game. Because of this the Intuitive Criterion is no longer sufficient to always select the unique stable outcome of the game. We thus use the $D_{1}$ refinement.

If we assume that the maximum willingness to pay, $a$, is sufficiently large, the

\footnotetext{
${ }^{5}$ For an excellent exposition of signaling games satisfying single crossing see Cho and Sobel (1990).
} 
chosen actions by both players will be strictly positive. An isoprofit curve for a monopolist of type $i$, which represents the combinations of quantities $q_{1}$ and tariffs $\tau$ yielding the same profit, $\bar{\pi}_{i}$, is implicitly given by

$$
\bar{\pi}_{i}=\pi_{i}\left(q_{1}, \tau\right)=q_{1}\left(a-q_{1}-c_{i}\right)+\frac{\delta\left(a-c_{i}-\tau\right)^{2}}{4(1-\delta)} .
$$

We now prove that our game falls into the subclass of signaling games with double crossing (all proofs are in Appendix A).

Lemma 1: Any two isoprofit curves $\left\{\bar{\pi}_{l}, \bar{\pi}_{h}\right\}$ can cross at most once in either of the two half-spaces defined by $\tau=2 q_{1}$. If the isoprofit curves have a point in common along $\tau=2 q_{1}$, then they are tangent at that point. Formally, the graph of the function $\tau=2 q_{1}$ divides $\left(q_{1}, \tau\right)$-space in such a way that at any $\left(q_{1}, \tau\right)$ the slope of $\bar{\pi}_{h}$ is bigger (smaller) (the same as) the slope of $\bar{\pi}_{l}$ whenever $\tau>(<)(=) 2 q_{1}$.

Lemma 1 states that the incentives for the two types to deviate from a given outcome differ depending on the relative sizes of $\tau$ and $q_{1}$. Consider first the case when $q_{1}>\tau / 2$ (i.e., relatively high quantity levels). This case is depicted graphically by point $B$ in Fig. 2 (and also by point $D$ in Fig. 3). Note that as graphed the firms' preferred set lies to the south of the isoprofit curves-for a given quantity, profit increases as the tariff falls. At the point of intersection $(B)$ the slope of isoprofit curve for the efficient type (type $l$ ) is bigger than the slope of inefficient type's isoprofit curve. This relationship can simply be interpreted as implying that at $B$ an increase in exports by $l$ is more profitable than ancrease by $h$.

Consider the other case, when $q_{1}<\tau / 2$. This case is depicted by the point $C$ in Fig. 3. At the point of intersection the slope of the isoprofit curve for the efficient type is smaller than the inefficient type's-implying that at $C$ an increase in exports by $l$ is less profitable than an increase by $h$.

Finally, if the two isoprofit curves have a point in common along the locus $\tau=2 q_{1}$, they must be tangent at that point. This case is depicted by the point $E$ in Fig. 4 and will be discussed at greater length in Section 4.4.

\subsection{Incentives to distort first period trade}

In this section we would like to investigate $l$ 's incentives to change its first period behavior in order to receive a more favorable tariff. If $l$ is not able to conceal its type, the optimal behavior involves producing its monopoly level, $q_{1 l}^{o}$-knowing that the state would meet its exports with $\tau_{l}^{o}$ any other strategy is inferior. This yields a first period profit of $\pi_{1 l}^{o}=\left(a-c_{l}\right)^{2} / 4$. From Eq. (5) the overall profit (over all periods) under complete information for $l$ is 


$$
\pi_{l}^{s} \equiv \frac{\left(a-c_{l}\right)^{2}(9-5 \delta)}{36(1-\delta)} .
$$

In order to characterize the incentives for $l$ to distort its trade, we construct the complete information isoprofit curve which is the locus of quantity-tariff pairs in Eq. (7) yielding $\pi_{l}^{s}$,

$$
q_{1}\left(a-q_{1}-c_{l}\right)+\frac{\delta\left(a-c_{l}-\tau\right)^{2}}{4(1-\delta)}=\pi_{l}^{s} .
$$

This isoprofit curve is depicted in Fig. 2. Since the firm's profits rise as the tariff falls, it prefers to reach the lowest possible isoprofit curve. Under complete information, the firm chooses a quantity, $q_{1 l}^{o}$, where the isoprofit curve is tangent to $\tau_{l}^{o}$.

For there to exist an incentive to signal at a minimum we must assume that the efficient type would rather export $q_{1 h}^{o}$ and receive $\tau_{h}^{o}$ (i.e., mimic $h$ ) than produce its complete information optimum and face high duties. Using Eq. (8) this amounts to requiring that

$$
\left(\frac{a-c_{h}}{2}\right)\left(a-\frac{a-c_{h}}{2}-c_{l}\right)+\frac{\delta\left(a-c_{l}-\left(a-c_{h}\right) / 3\right)^{2}}{4(1-\delta)} \geq \pi_{l}^{s} .
$$

Division by $\left(a-c_{h}\right)^{2}$ yields

$$
\frac{2 A-1}{4}+\frac{\delta(3 A-1)^{2}}{36(1-\delta)}-\frac{A^{2}(9-5 \delta)}{36(1-\delta)} \geq 0,
$$

where we have used a measure of the relative cost differential between the two types

$$
A \equiv \frac{a-c_{l}}{a-c_{h}}>1
$$

Solving Eq. (9) for $\delta$, it is straightforward to show that for all

$$
\delta \geq \delta^{m} \equiv \frac{9(A-1)}{2(7 A-5)}
$$

$l$ will choose to mimic. One can show that: (i) $\delta^{m}$ goes to zero as $A \rightarrow 1$; and (ii) $\delta^{m}$ increases monotonically to $9 / 14$ as $A \rightarrow \infty$. From this point on we will assume that the mimicking condition is satisfied. In Fig. 1 we graph $\delta^{m}$. The mimicking condition would be violated if $\delta$ is sufficiently small in comparison with the difference in marginal costs. In this case, the reduction in the efficient type's $(l)$ output in order to imitate the high cost producer is unacceptable given the low weight on future profits.

An important concern is not just whether for a given set of parameter values the isoprofit curves 'double cross' but also whether double crossing affects what 


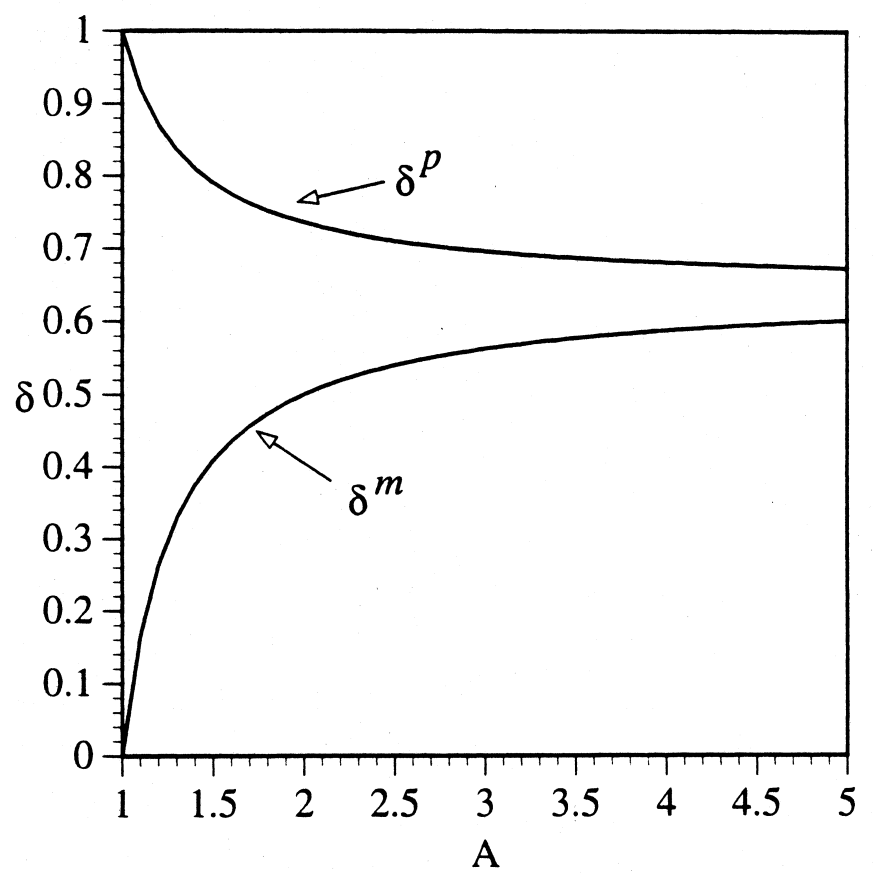

Fig. 1. Graph of $\delta^{m}$ and $\delta^{p}$.

equilibria are deemed reasonable. For reasons which will become clear, this question depends in large part on $l$ 's willingness to mimic $h$ at the point $\left(q_{1}=\tau_{h}^{o} / 2, \tau_{h}^{o}\right)$. From Eq. (7) the point $\left(q_{1}=\tau_{h}^{o} / 2, \tau_{h}^{o}\right)$ is weakly preferred by $l$ to the complete information profit whenever

$$
\left(\frac{a-c_{h}}{6}\right)\left(a-\frac{a-c_{h}}{6}-c_{l}\right)+\frac{\delta}{4(1-\delta)}\left(a-c_{l}-\frac{a-c_{h}}{3}\right)^{2} \geq \pi_{l}^{s} .
$$

Using our measure of the relative cost differential, $A$, this condition is satisfied if

$$
\delta \geq \delta^{p} \equiv \frac{(3 A-1)^{2}}{14 A^{2}-12 A+2} .
$$

We also graph $\delta^{p}$ in Fig. 1. It is clear that $\delta^{p} \geq \delta^{m}$ for all $A$. This strict ordering makes it convenient to break the analysis of the game into two parts: when $\delta<\delta^{p}$ and $\delta \geq \delta^{p}$.

\subsection{Equilibria when $\delta^{m} \leq \delta<\delta^{p}$}

As we will now show, when $\delta^{m} \leq \delta<\delta^{p}$ the unique stable equilibrium of the game is separating, i.e., those where each type exports a distinct quantity in the first period with probability one. In any such situation the true types are revealed 
and if this is to be a sequential equilibrium outcome, the efficient firm (type $l$ ) must produce its monopoly level. Hence, his separating equilibria profit will be $\pi_{l}^{s}$ and the separating equilibria isoprofit curve will be given by Eq. (8).

It is easy to check that the incentive constraint Eq. (8) implicitly defines a function which is strictly concave in $q_{1}$ and symmetric around $q_{1 l}^{o}$. This isoprofit curve yields an open set of quantities around $q_{1 l}^{o}, S=\left(q_{1}, \bar{q}_{1}\right)$, which $l$ would prefer to its equilibrium strategy if the response was $\tau_{h}^{o}$. The end points of this interval $\operatorname{are}^{6}$

$$
\begin{aligned}
& \underline{q}_{1}=\left(a-c_{l}\right) / 2-(1 / 6) \sqrt{\left(c_{h}-c_{l}\right)\left(4 a-5 c_{l}+c_{h}\right) \delta /(1-\delta)} \\
& \bar{q}_{1}=\left(a-c_{l}\right) / 2+(1 / 6) \sqrt{\left(c_{h}-c_{l}\right)\left(4 a-5 c_{l}+c_{h}\right) \delta /(1-\delta)}
\end{aligned}
$$

For every export level $q_{1} \in S$ we have $\pi_{l}^{s}<\pi_{l}\left(q_{1}, \tau_{h}^{o}\right)$. Therefore, in any pure strategy separating equilibrium the inefficient type must export $q_{1} \in S^{c}$, the complement of $S$.

Note that as $\delta$ goes to one, $S$ tends monotonically to $\mathbb{R}$. In other words, the set of quantities at which $l$ is willing to mimic $h$ if that would convince the home country to levy $\tau_{h}^{o}$ expands the more important is future profit. Note also that since: (i) $S$ is symmetric around $q_{1 l}^{o}$; (ii) $q_{1}<q_{1 h}^{o}<q_{1 l}^{o}<\bar{q}_{1}$; and (iii) the profit function of $h$ is symmetric about $q_{1 h}^{o}$ (given $\tau_{h}^{o}$ ), it follows that the profit for $h$ at $\underline{q}_{1}$ is higher than at $\bar{q}_{1}$. In fact, because $h$ 's profit is monotonically increasing up to $\bar{q}_{1 h}^{o}$ and decreasing thereafter, $\underline{q}_{1}$ is the unique maximizer among the set of separating equilibrium quantities. We can now show that

Proposition 1: Among the set of separating export levels for $h, q_{1 h}^{s}=q_{1}$ is the unique candidate to emerge in a $D_{1}$ equilibrium.

Proposition 1 provides us with a unique candidate for a separating equilibrium strategy for $h$ by assigning reasonable beliefs on $S^{c}$. However, to support this candidate as part of a $D_{1}$ equilibrium we must first assign beliefs on $S$. In addition, we must also check for the existence of pooling equilibria.

From Eq. (7) it is obvious that the isoprofit curve depends critically on $\delta$. As we will show, this fact combined with Lemma 1 will imply different equilibrium outcomes of the game for different values of $\delta$.

It is straightforward to show that any isoprofit curve can cross the tangency locus at most once. Formally, $\pi_{i}\left(q_{1}^{\prime}=\tau^{\prime} / 2, \tau^{\prime}\right) \geq \pi_{i}\left(q_{1}, \tau\right)$ implies $\pi_{i}\left(q_{1}^{\prime \prime}=\tau^{\prime \prime} / 2\right.$, $\left.\tau^{\prime \prime}\right)>\pi_{i}\left(q_{1}, \tau\right) \forall \tau^{\prime \prime}<\tau^{\prime}$. Combined with the restriction that $\delta<\delta^{p}$ this fact implies that $\tau_{h}^{o} / 2<q_{1}, \forall q_{1} \in S$. In other words, whenever $\delta<\delta^{p}$ the analysis identical to

\footnotetext{
${ }^{6}$ In order to compact the strategy spaces of the players we will assume that a type which is indifferent between its proposed equilibrium action and another quantity will follow the former.
} 
that of games which satisfy the standard single crossing property, allowing us now to claim that no pooling equilibrium outcome can survive the $D_{1}$ criterion.

Proposition 2: There do not exist any $D_{1}$ pooling equilibria when $\delta<\delta^{p}$.

Proposition 1 states that $\underline{q}_{1}$ is the unique candidate for a $D_{1}$ equilibrium strategy for $h$ among the pure separating export levels, and Proposition 2 rules out any pooling in stable outcomes. Indeed, as the next claim shows, $\underline{q}_{1}$ turns out to be a self-enforcing norm of behavior.

Proposition 3: The equilibrium outcome in which h exports $q_{1}$, l exports $q_{1 l}^{o}$, and the response of the government is $\tau_{h}^{o}$ and $\tau_{l}^{o}$, respectively, is the unique $D_{1}$ outcome of the tariff game for $\delta<\delta^{p}$.

The graphical representation of the equilibrium is provided in Fig. 2.

Besides completing the description of the unique stable equilibrium of the game, Proposition 3 illustrates another interesting phenomenon: the robustness of separation in monotonic signaling games where single crossing holds in the

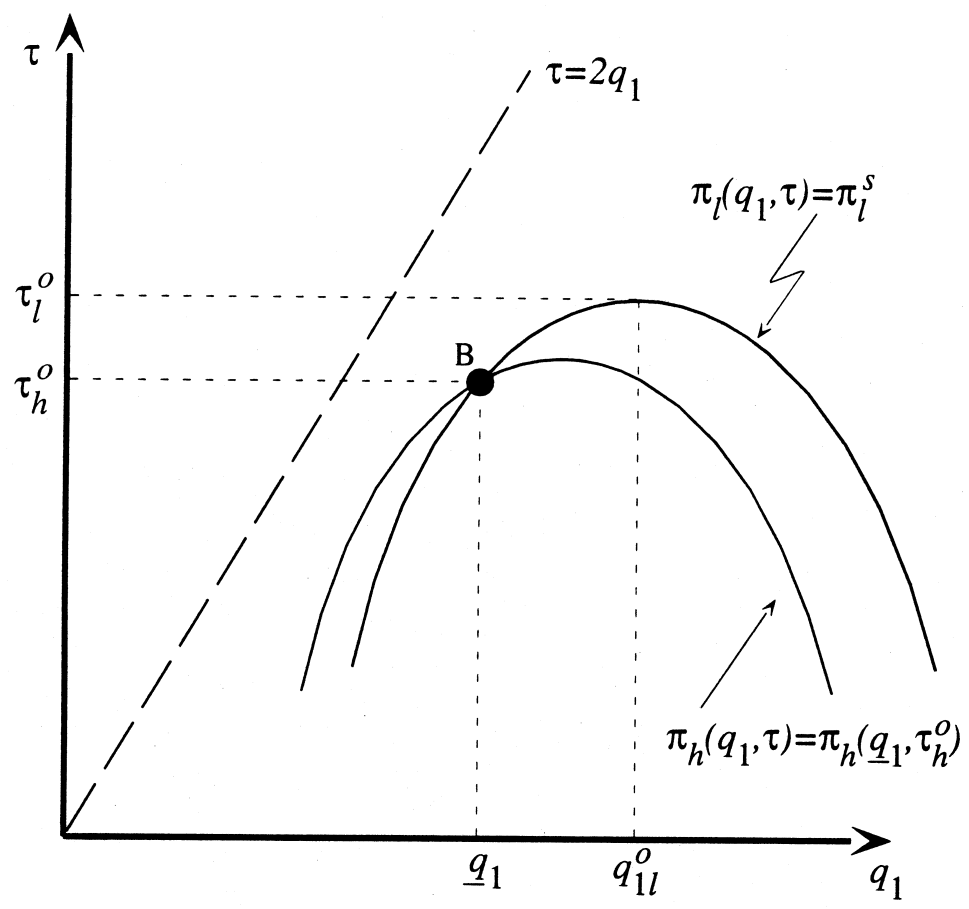

Fig. 2. The $D_{1}$ separating equilibrium $\left(\delta^{m} \leq \delta<\delta^{p}\right)$. 
relevant range of the parameter space. Cho and Sobel (1990) show that if single crossing is a global property of a model, the unique $D_{1}$ outcome under standard regularity assumptions must be separating. We have just shown that even in a model with double crossing, there may be parameter ranges where single crossing characterizes the incentives, and the unique $D_{1}$ equilibrium is separating. We now show, however, that if the profit function of the firm satisfies the double crossing condition (as defined in Lemma 1) the outcome of the model may be pooling for other parameter ranges.

\subsection{Equilibrium when $\delta \geq \delta^{p}$}

It is clear that as $\delta$ becomes larger, $S$ becomes larger. Moreover, if $\delta$ becomes sufficiently large, $l$ will earn greater profit at $\left(q_{1}=\tau_{h}^{o} / 2, \tau_{h}^{o}\right)$ than it does at the separating equilibrium. Fig. 3 depicts a case when $\delta$ is sufficiently large so that this is the case. As depicted $\left(q_{1}=\tau_{h}^{o} / 2, \tau_{h}^{o}\right)$ lies in l's complete information weakly preferred set. We will show that $\pi_{l}^{s} \leq \pi_{l}\left(q_{1}=\tau_{h}^{o} / 2, \tau_{h}^{o}\right)$ is a necessary and

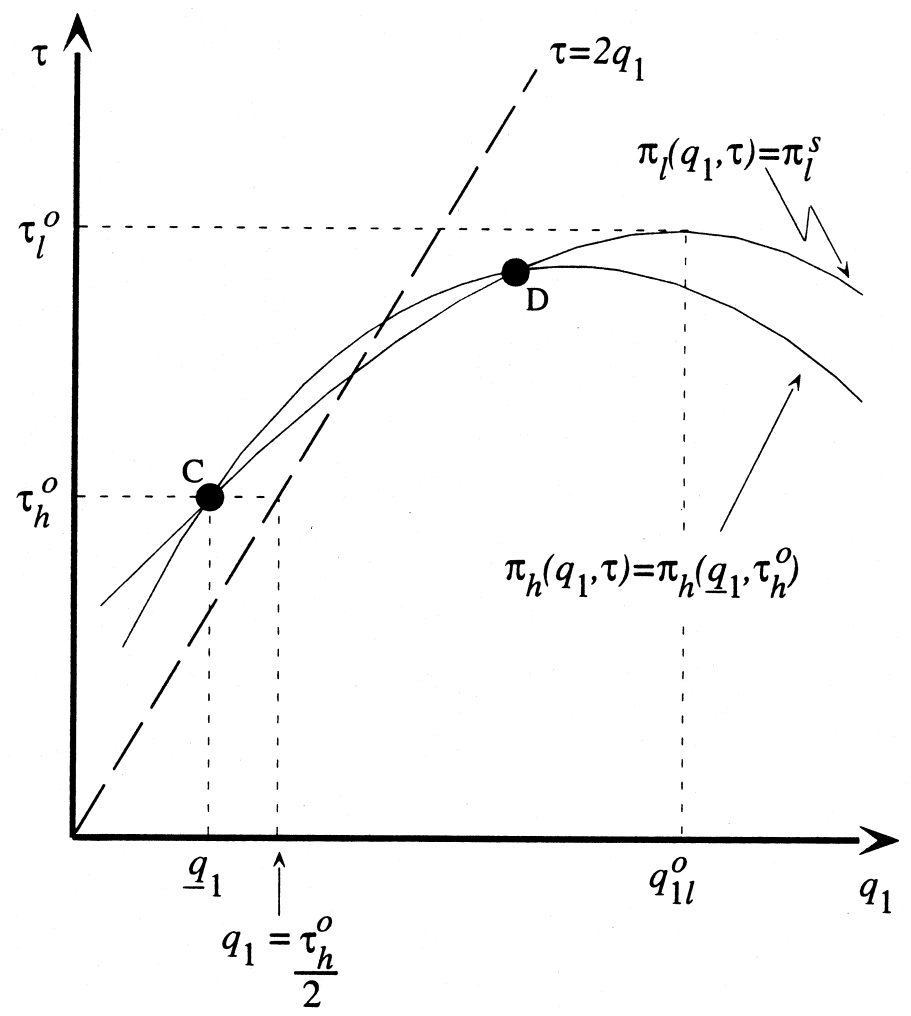

Fig. 3. The unique candidate for a $D_{1}$ separating equilibrium $\left(\delta \geq \delta^{p}\right)$. 
sufficient condition for pooling to emerge as the unique $D_{1}$ equilibrium outcome of the game. As shown in Section 2, this condition holds whenever $\delta \geq \delta^{p}$.

Following the steps in Proposition 1 we can show that the unique candidate for a $D_{1}$ separating equilibrium must involve $h$ exporting $\underline{q}_{1}$, if the latter exists. ${ }^{7}$ We now show, however, that assigning reasonable beliefs at out of equilibrium export levels leads to this solution being discarded.

Proposition 4: When $\delta \geq \delta^{p}$ there does not exist a pure strategy $D_{1}$ separating equilibrium.

Fig. 3 illustrates the intuition behind Proposition 4. The point $C$ depicts the unique candidate for a $D_{1}$ separating equilibrium. Suppose the monopolist contemplates slightly increasing its exports beyond $q_{1}$. At $C$ there is a greater range of sequentially rational tariffs that make this deviation profitable for the inefficient type than for the efficient type. Hence, the $D_{1}$ beliefs at exports levels slightly higher than $q_{1}$ lead $h$ to deviate from the proscribed separating equilibrium. Therefore, if $\delta \geq \delta^{p}$, the model will not have a pure strategy separating equilibrium.

Hence, if $D_{1}$ equilibrium exists, it must involve partial or pure pooling in first period quantities. We will show that such an equilibrium does indeed exist. Before constructing this outcome we need the following preliminary result which shows: (i) that if the isoprofit curves of the two types have a point in common along the tangency locus, then the isoprofit curve for $l$ is everywhere above the isoprofit curve for $h$; and (ii) that pooling can only occur along the tangency locus.

Lemma 2: Fix a $D_{1}$ outcome in which either type of monopolist exports $q_{1}^{p}$ with positive probability in the first period, and the response of the government is $\tau^{p}$. Then it must be that $q_{1}^{p}=\tau^{p} / 2$, and $\forall q_{1} \neq q_{1}^{p}, \pi_{l}\left(q_{1}^{p}, \tau^{p}\right)=\pi_{l}\left(q_{1}, \tau\right)$ and $\pi_{h}\left(q_{1}^{p}\right.$, $\left.\tau^{p}\right)=\pi_{h}\left(q_{1}, \tau^{\prime}\right)$ imply $\tau^{\prime}<\tau$.

Proposition 4 proves that if $\delta \geq \delta^{p}$ then a $D_{1}$ outcome (if it exists) must involve pooling. Lemma 2 establishes that the pooled quantity and the corresponding equilibrium tariff must lie along the tangency locus. Next we explicitly construct the unique $D_{1}$ outcome of the game thus showing that the necessary condition for pooling is also sufficient.

Proposition 5: If $\delta \geq \delta^{p}$ then there exists a unique $D_{1}$ equilibrium outcome which must involve pooling.

\footnotetext{
${ }^{7}$ If $q_{1}$ is not defined on the positive orthant then the claim that no sequential equilibrium is separating is trivial.
} 


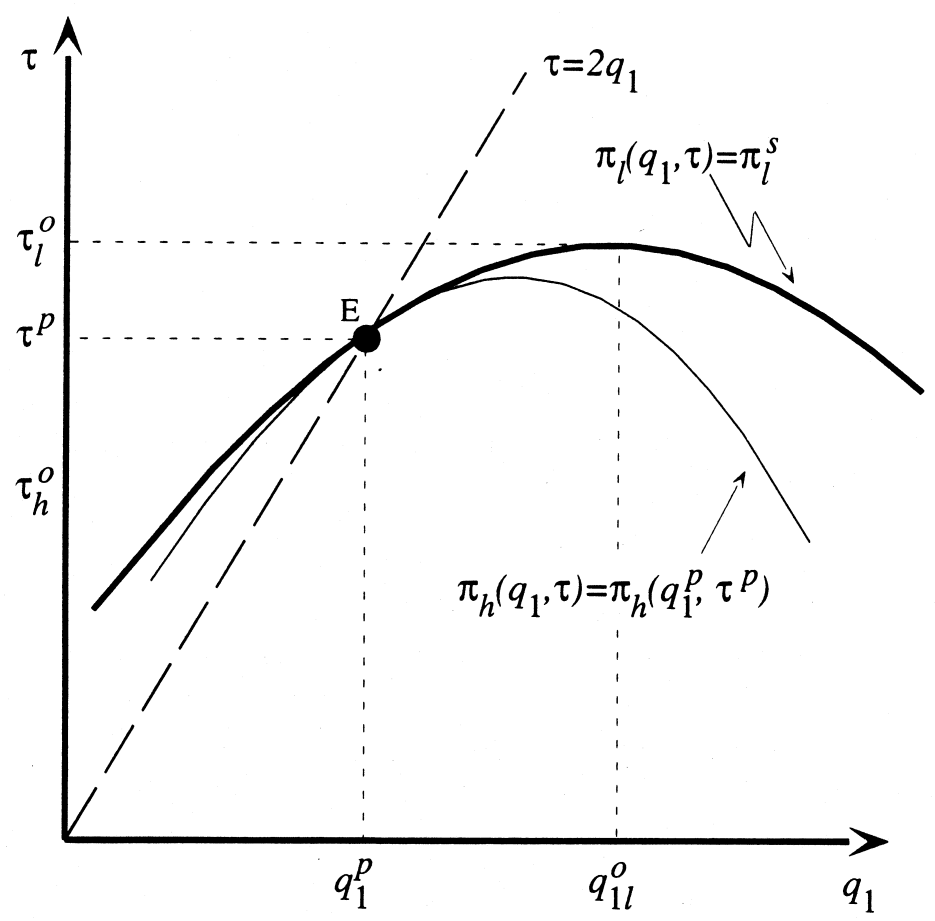

Fig. 4. The mixed pooling equilibrium of the game $\left(\delta \geq \delta^{p}\right)$.

The unique $D_{1}$ equilibrium outcome when the prior guarantees the existence of a mixed pool is depicted in Fig. 4. Note that in order to clearly highlight the fact that the isoprofit curves are tangent we have drawn $l$ 's isoprofit curve using a thicker line.

Proposition 5 is the key result of the paper. If a government does not have complete information about the foreign monopolist's costs, a policy of discriminatory tariffs will not be successfully implemented whenever the discount rate is sufficiently large. This significantly weakens the policy, since the government can simply levy a uniform tariff ex ante without causing any output distortions.

Moreover, Fig. 1 suggests that pooling is the more relevant outcome. Recall that in order for signaling to cause any distortion relative to the complete information case, $\delta \geq \delta^{m}$. It is clear that the condition $\delta \geq \delta^{p}$ is satisfied for a large fraction of the relevant parameter space.

We conclude with one final remark. It is clear that in the pooling equilibrium outcome $l$ restricts its exports with positive probability, and would never increase 
exports above the complete information quantity. However, it is conceivable that $h$ might export more than its complete information optimum, $q_{1 h}^{o}$, in the pool. For this to happen three conditions must be met simultaneously:

1. $q_{1 h}^{o}$ must be smaller than $q_{1}=\left(a-c_{l}\right) / 6$, the intersection of the tangency line with $\tau=\tau_{l}^{o}$. This is the case if $A>3$.

2. The profit of $l$ at $\left(q_{1 h}^{o}, \tau=2 q_{1 h}^{o}\right)$ must be higher than $\pi_{l}^{s}$. One can show that this condition holds only if $A>3$, and if

$$
\delta>\frac{9(A-1)^{2}}{14 A^{2}-36 A+4}>\delta^{p}
$$

Both of these conditions are significantly more difficult to achieve than the thresholds sufficient for pooling to emerge as a $D_{1}$ equilibrium.

3. The prior probability of $l$ should be sufficiently large so that $\tau^{e}>2 q_{1 h}^{o}$, where $\tau^{e} \equiv \mu \tau_{l}^{o}+(1-\mu) \tau_{h}^{o}$ is the ex ante optimal tariff. In particular, it must be that $\mu>2 /(A-1)$.

It seems unlikely for this unusual result (that $h$ 's exports increase in the pool) to hold. In addition, independent of $h$ 's output relative to its complete information monopoly level, the welfare analysis below shows that in general discriminatory tariff protection lowers welfare relative to uniform tariff.

\section{Welfare implications of incomplete information}

We would now like to determine whether a policy of discriminatory tariffs raises expected welfare. As shown in Sections 4.3 and 4.4 the equilibrium under the discriminatory tariff policy depends on the discount rate: if $\delta^{m} \leq \delta<\delta^{p}$ the unique equilibrium is separating while if $\delta \geq \delta^{p}$ the unique equilibrium is pooling.

In looking for a suitable benchmark for comparison, we consider two commonly observed alternatives: a uniform tariff and free trade. As compared to either benchmark a discriminatory policy involves costly output distortions and often lower welfare.

\subsection{Uniform tariff benchmark}

Consider a scenario where the home country can precommit itself to a uniform tariff. This alternative scenario is plausible if there are bilateral or multilateral trade arrangements which prevent the importing country from raising its tariff in later periods. This would credibly remove the possibility for differential tariff treatment and hence eliminate the incentives of the exporting firm to signal its technology through quantity restraints. 
Assuming the uniform tariff is designed in order to maximize expected welfare, using Eq. (3) we can show the optimal tariff is

$$
\tau^{\mathrm{U}}=\mu\left(a-c_{l}\right) / 3+(1-\mu)\left(a-c_{h}\right) / 3 .
$$

Note that $\tau^{\mathrm{U}}=\tau^{e}$.

Let us first consider the case when the primitives of the model give rise to the pooling equilibrium, i.e., for any $A$ such that $\delta \geq \delta^{p}$. Since the welfare in a mixed strategy equilibrium is rather tedious to compare we restrict ourselves to the case where the prior over the types induces pure pooling. ${ }^{9}$ In the pure pooling equilibrium both types export $q^{e}=\tau^{e} / 2$ in the first period under conditions of free trade, and produce their profit maximizing levels given $\tau^{e}$ in the subsequent periods. By contrast, under the uniform tariff scenario the monopolist produces its complete information optimum quantity, $q_{1 i}^{o}$, and faces $\tau^{\mathrm{U}}$ in the subsequent periods. Using our measure of the relative cost differential and substituting into Eq. (3), the difference in welfare $(\Omega)$ is easily derived as

$$
\Omega^{\text {pool }}(\mu, A) \equiv w^{\text {pool }}-w^{\mathrm{U}}=(1 / 72)\left(\mu^{2}(A-1)^{2}-9 \mu A^{2}+2 \mu A+7 \mu-8\right) .
$$

One can show that $\Omega^{\text {pool }}(\mu, A)<0$ for all $(\mu, A)$, implying

Proposition 6: If the primitives of the model induce pure pooling in equilibrium, then relative to an optimal uniform tariff a discriminatory tariff policy always lowers welfare.

Let us now consider the case when the primitives of the model induce separation in equilibrium, i.e., for any $A$ such that $\delta^{m} \leq \delta<\delta^{p}$. In this scenario the type $l(h)$ firm exports $q_{1 l}^{o}\left(q_{1}\right)$ in the first period and $q_{t l}^{o}\left(q_{t h}^{o}\right)$ in subsequent periods. Using our measure of the relative cost differential, the difference in welfare is

$$
\begin{aligned}
\Omega^{\mathrm{sep}}(\delta, \mu, A) & \equiv w^{\mathrm{sep}}-w^{\mathrm{U}} \\
& =\beta_{1}\left[\beta_{2}-6 A \sqrt{\beta_{2}}+3 \mu(A-1)^{2} \delta /(1-\delta)+9(A-1)(A+1)\right],
\end{aligned}
$$

where $\beta_{1}=(1-\mu) / 72>0$ and $\beta_{2}=(A-1)(5 A-1) \delta /(1-\delta)>0$.

Depending on the parameters $\Omega^{\mathrm{sep}}(\cdot) \gtreqless 0$. Nevertheless, we are able to characterize the welfare effect by making the following observations. First, at $\delta=\delta^{m}$, $\Omega^{\mathrm{sep}}(\cdot)>0$ for all $(\mu, A)$; this implies that a discriminatory tariff raises welfare for small $\delta$. Second, we can show that $\mathrm{d} \Omega^{\mathrm{sep}}(\cdot) / \mathrm{d} \delta<0$ for all $(\mu, A)$. In other words, a discriminatory tariff policy becomes less desirable as $\delta$ increases. Third, we can also show that at $\delta=\delta^{p}, \Omega^{\text {sep }}(\cdot) \gtreqless 0$ and that the sign depends on $\mu$ and $A$. In Fig. 5 we depict the zero contour for $\Omega^{\mathrm{sep}}(\cdot)$ at $\delta=\delta^{p}$. Clearly, the smaller is $A$, the

\footnotetext{
${ }^{8}$ While not written explicitly, it is important to recall that $\delta^{m}$ and $\delta^{p}$ are functions of $A$.

${ }^{9}$ This scenario would become exceedingly likely the larger is the discount rate.
} 


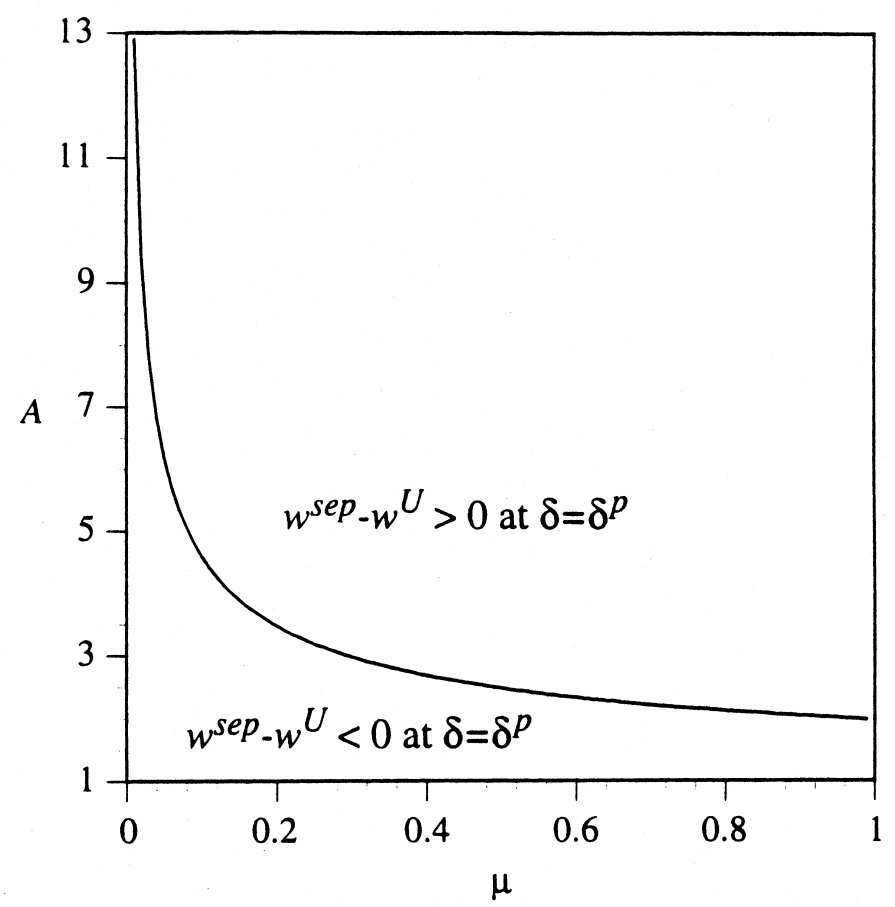

Fig. 5. Zero contour of $w^{\mathrm{sep}}-w^{\mathrm{U}}$.

greater is the range of $\mu$ in which $\Omega^{\text {sep }}(\cdot)<0$. Note that since typically one would expect $A<2$ the relevant region for all $\mu<1$ is $\Omega^{\text {sep }}(\cdot)<0$ at $\delta=\delta^{p}$.

Taken together we know that if $\Omega^{\mathrm{sep}}\left(\delta=\delta^{p}, \mu, A\right)<0$, then by continuity and monotonicity of $\Omega^{\mathrm{sep}}(\cdot)$ in $\delta$ there exists a function $\hat{\delta}(\mu, A)<\delta^{p}$ such that $\Omega^{\mathrm{sep}}(\hat{\delta}(\mu, A), \mu, A)=0$. Formally, define

$$
\bar{\delta}(\mu, A)=\left\{\begin{array}{cc}
\hat{\delta}(\mu, A) & \text { if } \Omega^{\mathrm{sep}}(\cdot)<0 \text { at } \delta=\delta^{p}, \\
\delta^{p} & \text { otherwise. }
\end{array}\right.
$$

We can now summarize our discussion as follows,

Proposition 7: If the primitives of the model are such that $\delta>\bar{\delta}(\mu, A)$ then a discriminatory tariff policy lowers welfare regardless of whether the outcome of the game is separation or pooling.

\subsection{Free trade benchmark}

Many economists believe that independently of GATT, free trade is a policy that a government can commit more easily to than a uniform tariff. For this reason, we 
now consider how the pure pooling outcome compares to free trade. We will show that for a substantial range of the parameter space free trade is the preferred policy. This result is quite remarkable when one considers the standard rent extraction motives for levying tariffs in this model. Free trade involves sacrificing many periods of tariff revenue and the fact that it may nonetheless be preferred highlights the potential costs of discriminatory tariff policy under incomplete information.

Using our measure of the relative cost differential and substituting into Eq. (3), the difference in welfare is

$$
\Psi(\delta, \mu, A) \equiv w^{\text {pool }}-w^{\mathrm{FT}}=[1 /(72(1-\delta))]\left[\beta_{3} A^{2}+\beta_{4} A+\beta_{5}\right],
$$

where $w^{\mathrm{FT}}$ denotes the welfare under free trade, $\beta_{3}=(-2 \delta-1) \mu^{2}+9(1-\delta) \mu$, $\beta_{4}=(4 \delta+2) \mu^{2}-(4 \delta+2) \mu$ and $\beta_{5}=(-2 \delta-1) \mu^{2}+(13 \delta-7) \mu-11 \delta+8$.

One can easily verify that $\Psi$ increases in $\delta$, implying that free trade becomes less desirable as the discount factor rises. This makes sense because the pooling outcome generates a stream of tariff revenue and this revenue becomes increasingly important as $\delta$ rises.

However, we can also show that as $\delta$ approaches $\delta^{p}$ free trade becomes the more desirable policy. Solving $\Psi(\delta, \mu, A)=0$ in $\delta$ yields

$$
\delta^{\mathrm{FT}}(\mu, A)=\frac{-(A-1)^{2} \mu^{2}+\left(9 A^{2}-2 A-7\right) \mu+8}{2(A-1)^{2} \mu^{2}+\left(4 A+9 A^{2}-13\right) \mu+11} .
$$

The monotonicity of $\Psi$ in $\delta$ implies that for all $\delta^{p} \leq \delta<\delta^{\mathrm{FT}}$ free trade is the preferred policy. One can show that for any $A, \delta^{\mathrm{FT}}$ reaches its minimum of 8/11 when $\mu=0$ and $\mu=1$. This fact in conjunction with the fact that $\delta^{p}$ goes to $9 / 14$ as $A$ increases implies that there is a substantial range of parameters where free trade is the preferred policy. In Fig. 6 we plot $\delta^{\mathrm{FT}}$ for $\mu=0.5$ (using a dotted line) along with $\delta^{m}$ and $\delta^{p}$. The fact that in general the discriminatory tariff policy only raises welfare relative to free trade for large $\delta$ reflects how incomplete information reduces the desirability of trade policies motivated by rent extraction.

\section{Conclusion}

The model developed here highlights an issue often ignored in the literature on optimal tariff regimes: the desire of importing countries to discriminate on the basis of foreign monopolist's technology is likely to provoke an undesirable strategic reaction by the monopolist in the form of reduced trade. Typically, the equilibria in signaling games involve separation and hence only the player with attractive information alters its behavior. In our model this would mean that only the firm with high costs would reduce exports relative to their profit maximizing level. This is the case when the discount rate is relatively small. However, when 


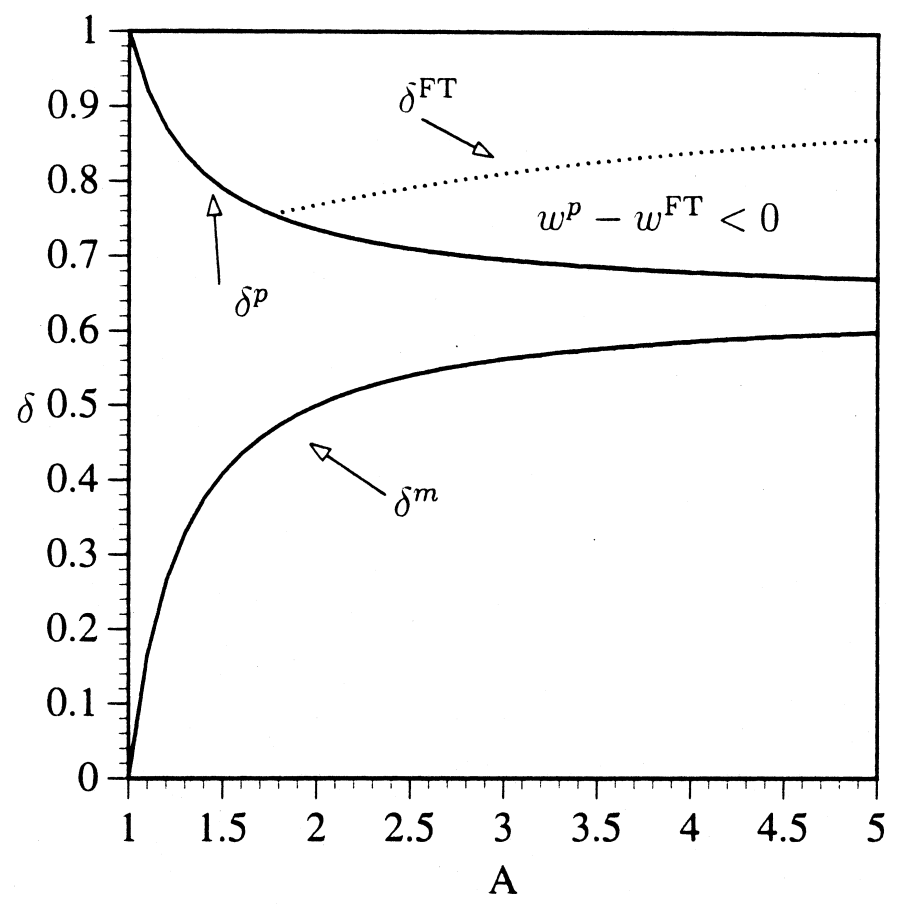

Fig. 6. Graph of $\delta^{\mathrm{FT}}(\mu=0.5), \delta^{m}$ and $\delta^{p}$.

the discount rate is relatively large the unique outcome involves pooling where exports are restricted regardless of the true type of the foreign firm.

Our analysis shows that incomplete information makes it very difficult, if not impossible, to implement a policy of discriminatory tariffs and highlights the difficulties in making clear-cut policy recommendations when faced with the unavoidable ambiguity associated with pooling equilibrium. Given this, we show that a policy of optimal uniform tariffs is generally superior to one of discriminatory tariffs. The results from this paper complement other recent work on trade policy with incomplete information in two important ways. First, we adopt a signaling approach to model the government's informational asymmetry while most of the other literature uses a screening approach. Second, we emphasize the relevance of pooling outcomes while the other research in this area emphasizes separation. Taken together this body of work severely draws into question the welfare benefits of trade policies aimed at rent extraction.

Also, we believe an important methodological contribution of the paper is the description of double crossing property of the payoff function. We show that this phenomenon gives rise to a pooling outcome. We hope that our analysis will lead 
other researchers to question the plausibility of separating equilibria when single crossing is not satisfied.

Finally, we note a few extensions. First, the unique stable pooling equilibrium outcome can be arrived at in other reasonable ways, not just through our assumption that the tariff is in place for many periods. Any factor that increases the marginal impact of tariffs on the exporter's payoff decreases the likelihood of pure strategy separating equilibria. For instance, consider a model where there are only two periods, one before the tariff is levied and one after. If demand grows over time then one can show that the unique equilibrium is the same as that derived in Section 4.4. Second, one can alternatively view the government's objective as maximizing tariff revenue only. It is straightforward to show that this again makes pooling more likely and hence exacerbates the welfare consequences. Third, the qualitative features of the model remain similar if we consider a foreign duopoly or if we allow for domestic production. The latter model is of significant practical interest since the attempt to tariff discriminate among exporters is not feasible under the MFN clause of the WTO. The presence of domestic production serves as an excuse for the proliferation of contingent measures of protection such as antidumping duties. The introduction of additional strategic players adds some new aspects to the interactions without altering the results significantly.

\section{Acknowledgements}

We would like to thank Reiko Aoki, Pradeep Dubey, John Hillas, Rich McLean and Daijiro Okada for helpful suggestions. This paper has benefited from the suggestions of two anonymous referees and also the comments of seminar participants at State University of New York-Stony Brook, New York University, Penn State University, Georgetown University and University of Florida.

\section{Appendix A}

\section{Proof of Proposition 1}

Fix a sequential separating equilibrium outcome obtained from $h$ exporting $q_{1}^{*} \in S^{c}, q_{1}^{*} \neq q_{1}$ and $l$ exporting $q_{1 l}^{o}$, where $S^{c}$ is the complement of $S$. Take an out-of-equilibrium message $q_{1}^{\prime} \in S^{c}$ such that $\left|q_{1}^{*}-q_{h}^{o}\right|>\left|q_{1}^{\prime}-q_{h}^{o}\right|$.

Let us construct the sets of sequentially rational responses of the government to $q_{1}^{\prime}$ which would make each type break the equilibrium. By the definition (incentive compatibility) of $S$ no tariff $\tau \in\left[\tau_{h}^{o}, \tau_{l}^{o}\right]$ would make $l$ deviate from $q_{1 l}^{o}$ to $q_{1}^{\prime}$ regardless of the beliefs which this would generate. Continuity and monotonicity of $h$ 's profit function guarantee that exporting $q_{1}^{\prime}$ would be strictly preferred to $q_{1}^{*}$ if that would make the country impose $\tau_{h}^{o}$. Hence, 


$$
E_{l}^{0}\left(q_{1}^{\prime}\right) \cup E_{l}\left(q_{1}^{\prime}\right) \subseteq E_{h}\left(q_{1}^{\prime}\right)
$$

and because this condition holds the $D_{1}$ criterion of Cho and Kreps (1987) requires the beliefs of the receiver to place probability one on $h$ at $q_{1}^{\prime}$. This would clearly make $h$ defect from the equilibrium we set out to check.

As the same reasoning applies to all $q_{1}^{*} \neq q_{1}$ it follows that the unique candidate separating $D_{1}$ equilibrium outcome is the one arising from $h$ exporting $\underline{q}_{1}$.

\section{Proof of Lemma 1}

Implicit differentiation of Eq. (7) at any $\left(q_{1}, \tau\right)$ yields a slope of an isoprofit curve given by

$$
s\left(q_{1}, \tau\right)=\frac{\mathrm{d} \tau}{\mathrm{d} q_{1}}=\frac{\left(2 a-4 q_{1}-2 c\right)(1-\delta)}{(a-\tau-c) \delta} .
$$

Differentiating $s(\cdot)$ with respect to $c$ at any $\left(q_{1}, \tau\right)$ yields

$$
\frac{\mathrm{d} s(\cdot)}{\mathrm{d} c}=\frac{-2(1-\delta)\left(2 q_{1}-\tau\right)}{\delta(a-\tau-c)^{2}}
$$

and the second part of the lemma follows. The first part follows from Eq. (A.1) in conjunction with monotonicity (the payoff of the monopolist is strictly decreasing in $\tau$ ). In particular, any two isoprofit curves can cross at most once in any of the two half-spaces defined by the tangency locus, $\tau=2 q_{1}$.

\section{Proof of Proposition 2}

Note first that the incentive compatible constraint Eq. (8) for $l$ implies that the only possible levels of exports which can arise in a sequential pooling equilibrium must be in $S$.

Suppose that both types export with positive probability quantity $q_{1}^{*}$ in the first period, the sequentially rational response of the government is $\tau^{*} \in\left(\tau_{h}^{o}, \tau_{l}^{o}\right)$, and the profit is $\pi_{i}^{*}$. Lemma 1 proved that the slope of the equilibrium isoprofit curve of $h$ at $\left(q_{1}^{*}, \tau^{*}\right)$ is strictly smaller than the corresponding isoprofit curve for $l$. This implies that at a $q_{1}^{\prime}$, which is $\epsilon$-smaller than $q_{1}^{*}$, the set of best responses which make $q_{1}^{\prime}$ weakly preferred by $l$ to $q_{1}^{*}$ is a subset of the set of best responses which $h$ strictly prefers to $q_{1}^{*}$. Hence in a $D_{1}$ equilibrium the beliefs of the government should place probability one on $q_{1}^{\prime}$ being exported by $h$, and the corresponding tariff would be $\tau_{h}^{o}$. Since in a pooling sequential equilibrium $\exists \Delta>0$ such that $\tau^{*}-\tau_{h}^{o}>\Delta$, by continuity and strict monotonicity of the profit function in $\tau, \exists \epsilon$ such that $\left|q_{1}^{\prime}-q_{1}^{*}\right|<\epsilon$ and $\pi_{h}^{*}<\pi_{h}\left(q_{1}^{\prime}, \tau_{h}^{o}\right)$. This would induce $h$ to break the proposed pool and export $q_{1}^{\prime}$. 


\section{Proof of Proposition 3}

All we need to do is construct off equilibrium beliefs consistent with the $D_{1}$ criterion and check that $h$ would not deviate from the prescribed equilibrium.

We have shown that if $\delta<\delta^{p}$ then the slope of the $h$ 's isoprofit curve is smaller than that of $l$ at $q_{1}$. Lemma 1 and the monotonicity of the profit functions in $\tau$ ensure that in each half space any two isoprofit curves intersect at most once. Hence the isoprofit curve of $h$ through $\left(\underline{q}_{1}, \tau_{h}^{o}\right)$ is below that of $l$ for all $q>\underline{q}_{1}$, and above that of $l$ otherwise. In a $D_{1}$ equilibrium the government should place probability one on $l$ for output levels higher than $q_{1}$, and zero at $q<q_{1}$. Since (as shown in Proposition 1) $q_{1}$ is the best for $h$ among the choices met with $\tau_{h}^{o}$, and any other quantity in combination with $\tau_{l}^{o}$ is strictly inferior to the given equilibrium strategy (the separating equilibrium curve for $l$ is everywhere below the line $\tau=\tau_{l}^{o}$ and so is that of $h$ ), $h$ has no incentive to deviate from $q_{1}$.

\section{Proof of Proposition 4} $h$.

The claim, as we noted, is equivalent to proving that $\underline{q}_{1}$ is not a $D_{1}$ strategy for

Let us fix the outcome arising from $h$ exporting $\underline{q}_{1}$. By assumption $\delta \geq \delta^{p}$ which implies $q_{1}<\tau_{h}^{o} / 2$; i.e., the isoprofit curve of $h$ through $\left(q_{1}, \tau_{h}^{o}\right)$ has a bigger slope than $l$ 's (by Lemma 1). This implies that for $q_{1}^{\prime} \epsilon$-bigger than $q_{1}$ the set of sequentially rational tariffs weakly preferred to $\left(q_{1}, \tau_{h}^{o}\right)$ by $l$ in combination with $q_{1}^{\prime}$ is a subset of the best responses which $h$ strictly prefers to its equilibrium action. If the given equilibrium produces a $D_{1}$ outcome we should be able to support it with beliefs placing probability one on $h$ at $q_{1}^{\prime}$. Since, with $\tau_{h}^{o}$ fixed, the profit of $h$ is monotonically increasing at $q_{1}$, the inefficient exporter would deviate to $q_{1}^{\prime}$, thus upsetting the unique candidate for a $D_{1}$ pure strategy separating equilibrium outcome.

\section{Proof of Lemma 2}

First we want to show that at a point $\left(q_{1}, \tau\right)$ along $\tau=2 q_{1}$ the isoprofit curve of $h$ is below that of $l$. We have already established that any point along the $\tau=2 q_{1}$ locus is the unique intersection of the tangency locus with the isoprofit functions $\pi_{i}\left(q_{1}=\tau / 2, \tau\right)=\pi_{i}\left(q_{1}, \tau\right)$ so that any $q_{1}^{\prime}<q_{1}$ and $\tau^{\prime}$ such that $\pi_{i}\left(q_{1}=\tau / 2\right.$, $\tau)=\pi_{i}\left(q_{1}^{\prime}, \tau^{\prime}\right)$ implies $\tau^{\prime}>2 q_{1}^{\prime}$.

Assume that at $q_{1}^{\prime}<q_{1}=\tau / 2, \pi_{l}\left(q_{1}, \tau\right)=\pi_{l}\left(q_{1}^{\prime}, \tau^{\prime}\right)$ and $\pi_{h}\left(q_{1}^{\prime}, \tau\right)=\pi_{h}\left(q_{1}^{\prime}, \tau^{\prime \prime}\right)$ with $\tau^{\prime \prime}>\tau^{\prime}$, so that the isoprofit curve of $h$ through $\left(q_{1}, \tau\right)$ is above that of $l$. We will show that this assumption is inconsistent with the model. By monotonicity of the profit in $\tau$ we have

$$
\pi_{l}\left(q_{1}, \tau\right)=\pi_{l}\left(q_{1}^{\prime}, \tau^{\prime}\right)>\pi_{l}\left(q_{1}^{\prime}, \tau^{\prime \prime}\right) .
$$


Since $\tau^{\prime \prime}>2 q_{1}^{\prime}$, Lemma 1 shows that the slope of $h$ 's isoprofit curve through $\left(q_{1}^{\prime}\right.$, $\left.\tau^{\prime \prime}\right)$ is bigger than the corresponding slope for $l$. This translates into

$$
\pi_{l}\left(q_{1}, \tau\right) \geq \pi_{l}\left(q_{1}^{\prime}, \tau^{\prime \prime}\right) \Rightarrow \pi_{h}\left(q_{1}, \tau\right)>\pi_{h}\left(q_{1}^{\prime}, \tau^{\prime \prime}\right) .
$$

The last statement contradicts Eq. (A.2) and our construction of $\tau^{\prime \prime}$ as $\pi_{h}\left(q_{1}\right.$, $\tau)=\pi_{h}\left(q_{1}^{\prime}, \tau^{\prime \prime}\right)$. Similar arguments hold for $q_{1}^{\prime}>q_{1}$.

Next, note that in any pooling $D_{1}$ equilibrium it must be that the beliefs of the home country place probability one on $l$ for all disequilibrium messages at least in the neighborhood of the quantity. Otherwise, continuity and monotonicity of the firm's payoff function would break the proposed play (the proof would be similar to that of Proposition 3). This implies that the equilibrium isoprofit curve for $l$ must be above that of $h$ in this neighborhood, and tangent at the equilibrium message. According to the double crossing property of the firm's payoff given in Lemma 1 and the arguments in the first part of the proof these conditions are satisfied only along the tangency locus, $\tau=2 q_{1}$.

\section{Proof of Proposition 5}

As a preliminary step observe that in a $D_{1}$ pooling equilibrium $h$ must export the pooled quantity $q_{1}^{*}$ with probability one. The reason is as follows: if $\pi_{l}^{*}$ is the equilibrium payoff for $l$, it must be that $\pi_{l}^{*} \geq \pi_{l}^{s}$. Monotonicity in $\tau$ implies that for all $q_{1}$ the isoprofit curve yielding profit $\pi_{l}^{*}$ is below the complete information isoprofit curve for $l$. By Lemma 2 the response of the government to $q_{1}^{*}$ must be $\tau^{*}=2 q_{1}^{*}$ and the equilibrium isoprofit curve for $h$ giving payoff $\pi_{h}^{*}$ must be everywhere below the equilibrium curve for $l$. Since the locus defined by $\pi_{l}^{s}$ is under $\tau=\tau_{l}^{o}, \forall q_{1}$, the equilibrium payoff for $h$ must be strictly higher than producing any $q_{1}$ in combination with $\tau_{l}^{o}$.

The above description of the equilibrium isoprofit curves implies that $\forall q_{1} \neq q_{1}^{*}$ :

$$
E_{h}^{0}\left(q_{1}\right) \cup E_{h}\left(q_{1}\right) \subseteq E_{l}\left(q_{1}\right) .
$$

Hence in a $D_{1}$ equilibrium the beliefs of the government at $q_{1} \neq q_{1}^{*}$ must place probability one on $l$ and the corresponding tariff should be $\tau_{l}^{o}$. This would make $h$ export $q_{1}^{*}$ with probability one.

Suppose now that the prior probability of an $l$-type exporter, $\mu$, is such that $\pi_{l}^{s} \geq \pi_{l}\left(q^{e}=\tau^{e} / 2, \tau^{e}\right)$, where $\tau^{e}=\mu \tau_{l}^{o}+(1-\mu) \tau_{h}^{o}$ is the ex ante optimal tariff.

We claim that in this case $l$ can not pool with probability one in any sequential equilibrium. This follows from the fact that if $l$ pools with probability one, then the unique best response of the government would be $\tau^{e}$ to the quantity $q^{e}=\tau^{e} / 2$. The point $\left(q^{e}, \tau^{e}\right)$ is strictly inferior for $l$ compared to full separation at $q_{1 l}^{o}$. This implies that $l$ can not pool with probability one at $q^{e}$. Therefore, the only possibility for a solution must involve partial pooling.

As argued above, in any $D_{1}$ pooling equilibrium all disequilibrium tariffs will be 
$\tau_{l}^{o}$. The strict concavity of $l$ 's profit function will then guarantee that the only quantity produced with positive probability and met with $\tau_{l}^{o}$ is the unique maximizer, $q_{11}^{o}$. Moreover, the payoff from such an action must be equal to the payoff at the pooled message if $l$ is to randomize. This implies that the pool must occur at the point of intersection of $l$ 's complete information isoprofit curve Eq. (7) and the tangency locus. Call this quantity $q_{1}^{p}$. In order to make the corresponding tariff $\tau^{p}=2 q_{1}^{p}$ a sequentially rational response $l$ must randomize in such a way that the unique government's posterior about $l$ at $q_{1}^{p}$, $\eta$, should satisfy

$$
\tau^{p}=\eta \tau_{l}^{o}+(1-\eta) \tau_{h}^{o}
$$

In other words, the probability $\rho$ with which $l$ plays $q_{1}^{p}$ should determine its conditional probability given $q_{1}^{p}$ through

$$
\eta=\frac{\mu \rho}{\mu \rho+(1-\mu)}
$$

Thus we have shown the existence of a unique partial pooling $D_{1}$ equilibrium outcome for the case when $\pi_{l}^{s} \geq \pi_{l}\left(q_{1}=\tau^{e} / 2, \tau^{e}\right)$.

On the other hand, if $\pi_{l}^{s}<\pi_{l}\left(q_{1}=\tau^{e} / 2, \tau^{e}\right)$, then $l$ would rather pool at $q^{e}=\tau^{e} / 2$ than separate. The partial pooling equilibrium described in the preceding paragraph is not even sequential in this case since the posterior $\eta$ would require $l$ to export $q_{1}^{p}$ with probability larger than one (keep in mind that in any pooling $D_{1}$ equilibrium $h$ must pool with probability one). This shows that the only $D_{1}$ equilibrium is in pure strategies at exports $q^{e}$ and tariff level $\tau^{e}$. The offequilibrium response is $\tau_{l}^{o}, \forall q_{1} \neq q^{e}$.

\section{References}

Bagwell, K.W., Staiger, R.W., 1996. Reciprocal trade liberalization, National Bureau of Economic Research Working Paper No. 5488.

Banks, J.S., Sobel, J., 1987. Equilibrium selection in signaling games. Econometrica 55, 647-661.

Brainard, S.L., Martimort, D., 1997. Strategic trade policy with incompletely informed policymakers. Journal of International Economics 42, 33-66.

Brander, J.A., Spencer, B.J., 1984. Tariff protection and imperfect competition. In: Kierzkowsky, H. (Ed.), Monopolistic Competition and International Trade, Clarendon, Oxford, pp. 194-206.

Cho, I.K., Kreps, D.M., 1987. Signaling games and stable equilibria. Quarterly Journal of Economics 42, 179-221.

Cho, I.K., Sobel, J., 1990. Strategic stability and uniqueness in signaling games. Journal of Economic Theory 50, 381-413.

Collie, D., Hviid, M., 1993. Export subsidies as signals of competitiveness. Scandinavian Journal of Economics 95 (3), 327-339.

Collie, D., Hviid, M., 1994. Tariffs for a foreign monopolist under incomplete information. Journal of International Economics 37, 249-264.

Feenstra, R.C., 1995. Estimating the effects of trade policy. In: Grossman, G.M., Rogoff, K. (Eds.), Handbook of International Economics, Vol. 3, North-Holland, Amsterdam, pp. 1553-1595. 
Grossman, G.M., Helpman, E., 1994. Protection for sale. American Economic Review 84, 833-850.

Grossman, G.M., Helpman, E., 1995. Trade wars and trade talks. Journal of Political Economy 103, $675-708$.

Grossman, G.M., Helpman, E., 1995. The politics of free-trade agreements. American Economic Review 85, 667-690.

Hwang, H., May, C., 1991. Optimum discriminatory tariffs under oligopolistic competition. Canadian Journal of Economics 24 (3), 693-702.

Johnson, H., 1951. Optimum welfare and maximum revenue tariffs, Review of Economic Studies 19, 28-35.

Katrak, H., 1977. Multi-national monopolies and commercial policy. Oxford Economic Papers 29, 283-291.

Kolev, D., 1995. Monotonic signaling games with double crossing, Mimeo, State University of New York-Stony Brook.

Kreps, D.M., Sobel, J., 1994. Signaling. In: Aumann, R.J., Hart, S. (Eds.), Handbook of Game Theory, Vol. 2, North-Holland, Amsterdam, pp. 849-867.

Kreps, D.M., Wilson, R., 1982. Sequential equilibria. Econometrica 50, 863-894.

Krugman, P., 1984. Import protection as export promotion: International competition in the presence of oligopoly and economies of scale. In: Kierzkowsky, H. (Ed.), Monopolistic Competition and International Trade, Clarendon, Oxford, pp. 180-193.

Qiu, L., 1994. Optimal strategic trade policy under asymmetric information. Journal of International Economics 36, 333-354. 